Military Technical College Kobry El-Kobbah, Cairo, Egypt.

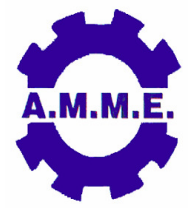

$15^{\text {th }}$ International Conference on Applied Mechanics and Mechanical Engineering.

\title{
HYDRAULIC COMPONENTS STANDARD MATHEMATICAL MODELS FOR APPLICATION ENGINEERS
}

\author{
M. K. Bahr \\ Director of Professional Education, Milwaukee School of Engineering \\ Chairman of Fluid Power Mathematical Modeling Committee \\ 1025 North Broadway, Milwaukee, WI, 53202-3109, USA \\ khalil@msoe.edu Tel: 414-940-2232 Fax: 414-277-7470
}

\begin{abstract}
In order for the hydraulic component manufacturers to compete in the very tough market, they must spend every effort to improve the characteristics of their components. End users of hydraulic components have different interests depending on the application e.g. cost, dynamics, efficiency, life time, operational conditions, sensitivity to contaminations, noise, etc. Therefore, $R \& D$ sections at the hydraulic component manufacturers are working day and night to investigate these issues through developing detailed models. In some cases, probably several models are to be developed for the same component where each model is dedicated to handle one prospective, e.g. one model for dynamic response, second model for thermal analysis, third model for stress analysis, etc.
\end{abstract}

Detailed models like these usually include dimensional parameters, operating conditions and fluid properties. Most of these design parameters are known to the component developer and considered critical and even classified info in the high tech industry. Additionally, some of these design parameters may require to be carefully assumed because it is not $100 \%$ known, e.g. viscous friction coefficients, leakage coefficient, etc.

These expensive component-level models that are developed at the manufacturer's site may be dedicated for specific component/size/ brand and are not applicable for other component/size/brand. Also it may be developed using software packages that are not available for public.

System-level design is a totally different environment. First of all, system designers have no access to all the critical design parameters of each component and it will be tough for them to run after every unknown design parameter in every component. Secondly, system designers are mostly interested only in the static and dynamic characteristics of each component regardless the inside construction of the component. 
System designer can mathematically model simple systems by a set of equations to be solved instantaneously. Part of the problem to follow such approach is that if the system layout is changed, the whole set of equation will be changed too. Therefore, system designer is mainly looking for more generic models that are flexible enough to be used repeatedly for similar components.

In the past decade, a number of software packages were found in the market. These packages contains library out of which the user may grab premade models for hydraulic components to use in a system design. These software packages may give access to the user to see the mathematics behind the model, but not give access to change the way the models have been built.

Recently a committee has been formed to formulate standard mathematical models for various fluid power components. The main objective is to standardize the mathematical models to facilitate the broader use, teaching and understanding of fluid power systems in solving application-specific problems. This will raise the technological level of the fluid power industry.

The purpose of this lecture is to update the audience about the mission of the committee, give a case study and recruit senior faculty to join the committee as a members or observers. 